\title{
Parts of the Whole: Approaching Education as a System
}

Dorothy Wallace

dorothy.wallace@dartmouth.edu

Follow this and additional works at: https://digitalcommons.usf.edu/numeracy

Part of the Mathematics Commons, and the Science and Mathematics Education Commons

\section{Recommended Citation}

Wallace, Dorothy. "Parts of the Whole: Approaching Education as a System." Numeracy 2, Iss. 2 (2009):

Article 9. DOI: http://dx.doi.org/10.5038/1936-4660.2.2.9 


\title{
Parts of the Whole: Approaching Education as a System
}

\author{
Abstract \\ An educational system is a highly coupled complex system of inputs, outputs, sensors and actuators. \\ Using an engineering perspective, this column begins the process of naming and categorizing parts of the \\ system. It then focuses on teachers as one part of a large system, and analyzes the forces that influence \\ how teachers work, and that draw or repel individuals to a teaching career. The growing shortage of \\ qualified teachers can be explained by properties of the system as a whole that determine the context in \\ which teachers do their job. \\ Keywords \\ education, management, systemic reform, policy \\ Creative Commons License \\ (c) (i) (8)
}

This work is licensed under a Creative Commons Attribution-Noncommercial 4.0 License 


\section{Parts of the Whole, A Column by D. Wallace}

\section{Approaching Education as a System}

When an engineer designs or fixes a complicated system, he or she relies on a model representing that system, pictured on paper or as a computer display. The model is a fundamentally mathematical object that attempts to picture all of the inputs to the system, all of the interrelationships among parts, the processes of the system, and the various outputs. Usually it looks like a lot of boxes connected by lines. Each box represents one important part of the system, and the connecting lines represent influences of one part on another: inputs, outputs, or forces. In a biological model, the boxes might be populations of organisms. In an engineering model, they might be parts of a factory process. In a business model, they might be supplies of products required to produce other products. A designed system usually includes sensors, which are devices that report some aspect of the state of the system at given times. The system also includes actuators, which are devices that can be activated automatically or at will to change the state of some part of the system. All of these are represented in the model. When a system needs to be adjusted, the box model helps everyone involved understand what actions the engineer is taking and why.

A school is a complicated system. If one were to represent it by a box model, one might include the teachers as one box and the principal as another. There might be a box for each grade level of student, with lines between them reflecting the fact that the output of grade 1 goes into grade 2 or else back into grade 1 . There would also have to be boxes representing interests outside the school that have a direct influence on it. Education is a system with many such inputs. State and local policymakers, national and state standards in various subjects, and local tax boards all attempt to influence the system by acting at fairly high levels of its hierarchy. Nonprofit foundations tug at education's sleeve by offering money for special projects. Private enterprise in the form of textbook publishers nearly dictates the "scope and sequence" of certain subjects in certain districts. The existence of private schools affects the system as a whole by removing a certain population of students from the public schools, along with the political commitment of the parents of those students. The private school can set its own goals, theoretically separate from any declared public agenda. These are examples of inputs that usually affect a school through its administrators, who then set internal policies that affect teacher behavior.

In a given classroom, the students are the major input. They come in with a spread of level of preparation, sophistication and maturity, breadth of experience, and age. The teacher must cope with this spread. Teachers themselves are an input to the system, with their own range of preparation, maturity and experience. Add to those factors a range of intellectual interests among teachers that is likely 
to have an impact in the classroom. Finally, there is the matter of teacher expectations of students, a factor that has been shown to be a very good predictor of student performance, a phenomenon that can be observed even if the teachers are graduate psychology students and the students are identical white rats.

Teacher preparation programs control both the quantity and quality of the specialized education teachers get. The college or university as a whole determines what other sorts of education teachers will have. For example, a college that requires a degree in a subject other than education will produce a teacher who has been educated in a substantially different way from one that offers a degree in education. These programs all interact with those who set state standards, as well as local teachers who supervise novices. Recertification requirements in a state may include evidence of professional development. Such a requirement is an actuator on the system that causes teacher and administrative behavior that would not be likely to happen otherwise.

One of the most important inputs, possibly the most important, to the educational system is the behavior of parents. The expectations parents set, the help they offer at home, the time set aside for study at home, all of these affect student performance. Parents, who allow children to watch upwards of seven hours of television a week (an hour a day!), are exerting considerable force on the educational system, although they may not look at it that way. A child who comes home, romps outside and gets some exercise, spends a little time doing homework, eats a healthy dinner and falls exhausted and happy into bed is going to have a very different day the next day from one that spends hours watching the television. The parents have enormous influence on the whole system of education, yet they are often a neglected component of interventions.

In addition to inputs, a well-designed system has sensors. These are devices built into the system that measure the activity of certain components and communicate these measurements to the engineer or to an automated device. The sensors get data on what the system is doing at a particular time, so that other devices (called actuators) can tweak the system back into the desired state. A good engineer builds in the minimal number of sensors required to know the state of the system, so that appropriate adjustments can be made. The fewest possible are desired because, typically, a sensor imposes a cost on the system, usually in terms of efficiency. In education our sensors consist mostly of standardized tests at various levels, report cards, and professional reviews. This amount of evaluation is already quite costly in actual dollars, and imposes a serious burden on the system, taking children out of class for days at a time to take tests, using up precious teacher time for reviews. Nonetheless, most of the sensors in education measure very few components of the system, often too late to help individual teachers make any reasonable adjustment.

These measurements can be completely misconstrued by those who manage education. Often, student performance on tests is interpreted as a measure of success of the individual teacher, rather than a measure of how the system as a 
whole is doing. This mistake has very harmful consequences for the whole system of education. It causes administrators to attempt to influence something (teacher behavior) that may be working fine and ignore everything else. The causes of the performance of a whole system usually reside at least partially in the "everything else." It is as if a mechanic, informed that your left front wheel is vibrating, looked only at the wheel and not at the axle, joints, or bearings. Not finding anything visibly wrong, the mechanic may replace the wheel anyway, just to be on the safe side, and to make you feel better. The problem is not solved, but at least expensive steps were taken.

The output of the educational system is a diverse group of people that includes every last one of us. Every carpenter, doctor, politician, parent, businessperson, teacher, voter or engineer is part of the output of the educational system. At each grade level there is also an input and an output.

Engineers work on systems that have been designed carefully by human beings. Each part of the system is designed separately and is well understood before the parts are assembled into a whole. Specific forms of mathematical modeling work well to predict the result of changes in such a system, but cannot be applied to education because the scale is too large and individual processes are not well enough understood. The most apropos approaches are likely to be of a statistical nature, coupled with an understanding of cognition and classroom practice. The educational system is more like a biological system: huge, diverse, complex and computationally somewhat intractable. Yet even biological systems are amenable to analysis and scrutiny, if the state of the system matters enough. Let us look at one particular component of the school system and see how an analysis of the forces on that one component might lead us to specific interventions.

Some properties of a system might be best understood by taking the point of view of a single part of it. One of Newton's laws goes like this: any force on a stationary object must be balanced by an equal and opposite force for the object to remain stationary. For example, consider a block hanging from a string. Clearly gravity exerts a downward force on the block, but the string also exerts an equal upward force on it. It is easier to understand this second force if you imagine yourself hanging by your own arm. You can feel both forces: the upward force that threatens to remove your arm from its shoulder socket and the downward force that is making your fingers slip. You feel the upward force that balances the gravity pulling downward. Without it, you would fall.

Teachers are central to the educational mission. Many forces act upon them, pulling in a variety of directions. Understanding what the teaching career looks like to the teacher is a useful way to catch a glimpse of the system as a whole.

Becoming a teacher in a public school requires a degree from a four-year college as well as a series of special courses that yields a certificate allowing the bearer to teach in a particular state. Many states have reciprocal agreements, so a teacher has some automatic mobility with certification. Often the college requires 
a degree in an academic subject separate from education, making the process of obtaining certification an add-on to the standard undergraduate curriculum. Many people obtain their certification after graduation, adding a year of study before starting work. The decision to become a teacher is a serious one, requiring a lot of preparation and commitment before ever entering the classroom.

After becoming certified, teachers must take a certain number of hours of professional development to maintain their certification. The educational requirement for teachers is ongoing. Teachers are required by the state to be lifelong learners. The decision to stay in teaching is a serious one, demanding a commitment to one's own ongoing education.

If you ask a K-6 teacher why he or she chose this career, probably you will hear that this person likes working with children. If you ask a college teacher, you will be likely to hear about that person's love of their subject. Somewhere in the years from 6th to 12th grade there is a transition in motivation on the part of teachers. Rarely will you hear that a person chose the teaching profession because of the pay, although in some parts of the country and in some districts teachers seem well paid compared to their neighbors. Occasionally one hears the nine-month employment schedule given as a motive. New teachers regard tenure as more of an obstacle than a prized reward.

Of course, there are other ways to enjoy children besides being a teacher. One could be a parent, for example, which is a far more popular choice. In fact, some states are experiencing a severe teacher shortage. In Texas, for example, a large proportion of teachers, lacking certification of any kind, are in the classroom on what is considered an "emergency" basis. These uncertified teachers did not participate in the system designed to prepare teachers. They are not eligible for tenure; thus they are outside the reward system designed to keep good teachers. An educational system that cannot influence the teachers in it will be very hard to manage. This column attempts to describe the forces influencing regular teachers, but it is important to keep in mind that not all teachers fit this description.

Although teachers do not generally enter the profession for the money, it is worth taking a look at how salaries compare with other jobs. The data here are taken from the Bureau of Labor Statistics, which maintains an extensive Web site. The Bureau reports that the estimated average salary of all public elementary teachers (excluding special education) in 2008 was $\$ 52,240$. On the other hand, median annual earnings of Postal Service clerks were $\$ 50,150$ in 2008 . As an example from the private sector, median annual earnings in 2008 for advertising and promotions managers were $\$ 94,720$; marketing managers, $\$ 118,160$; sales managers, \$110,390; and public relations managers, \$101,220. Insurance sales agents made an average of $\$ 92,050$. Working for the postal service does not require a college degree. Working in sales and marketing usually does, although it doesn't necessarily require any education besides or beyond that.

Teaching is unusual in that merely doing a good job of teaching is, alone, insufficient for remaining employed. One must obtain a certain number of hours 
of education toward re-certification and one must negotiate tenure. One must assuage parents who come with various complaints, either to the teacher or to the principal. With only a slight cut in pay, a person could go work at the post office and experience far less stress. Alternatively, one could work in business and, by merely being good at the job, make a lot more money. It is not surprising that any state with a good economy would be short of teachers. If the economy is good, then attempting to improve the education of teachers by placing more requirements on them, taken alone, is likely to have the reverse effect of discouraging the most competent people from entering the profession in the first place.

The early history of $\mathrm{K}-12$ education in this country shows a profession dominated by women who had few other options in life. They were paid little and worked hard. They were asked to leave the profession upon marrying, thus ensuring that no competitive force be brought to the profession by less desperate or better connected women. A set of expectations grew around teachers that today's profession has inherited, whether they are reasonable or not. It is not uncommon at town meetings in Vermont and New Hampshire to hear people with no college education (such as the person who grades the town roads) complain that a schoolteacher with twenty years of experience makes more money than they do. The investment that the teacher has made in his or her own education, the investment he or she has made in the town itself, is not expected to bear fruit. The selfless dedication of the otherwise unemployable schoolmarm of a hundred years ago is still the unspoken expectation. The fact that most K-6 teachers are women does nothing to improve this expectation. But the times, the teachers, and the forces upon those teachers-all have all changed. It is a complex decision to become a teacher, but a very easy one to leave the profession.

One way to look at the managerial problem is as a carrot-and-stick issue. Too many sticks, such as extra educational requirements, parental pressure, constant performance reviews, will result in insufficient people entering the profession. To balance the demands on teachers, these sticks need to be accompanied by carrots, such as competitive pay, support in the form of classroom assistance or a materials budget, and (not at all the least!) respect from the community. For some teachers, having the summer off is a benefit, but for others it just represents three months of part-time work at lower pay. In times of economic stress extra free time might not be seen as a benefit. The same goes for any changes toward improving teacher preparation. If a state can require the extra courses necessary to give teachers what they really need to improve their classes, can they also mandate a fair salary for those who go through the process? As with the forces keeping a hanging block in place, a balance of forces is necessary to keep a good teacher in the profession.

It is clear that a complete reworking of the reward structure is necessary in order to attract good people into teaching and motivate them to complete whatever educational processes turn out to be necessary for improving the 
educational system as a whole. It is also possible to identify some forces on teachers that are outside the educational system, but which the reward structure must nonetheless address. First among these is burnout. It is possible to become bored and tired with working at the post office, but the mail will not notice. It is possible to become exhausted and short tempered in advertising, but as long as the work gets done it doesn't matter. An exhausted, short-tempered, or bored teacher is a disaster in the classroom. Furthermore, it is likely that such a teacher became exhausted or short tempered or bored, partly as a result of the job of teaching.

Therefore, one way to improve classrooms in a straightforward, humane way is to provide a generous and well thought out bailout mechanism for people who are done with teaching, except for the actual job of it. A good early-retirement package, free training in another profession, a job placement service-any kind of assistance with transition would be to the point here. Such services would be far more cost effective than keeping a poor and reluctant teacher in the classroom. Like the Peace Corps or the military, teaching is a difficult public service. The time frame should be limited, with numerous options for voluntary exit. Perhaps a strategy like this one would also increase the numbers going into teaching, because the prospect of teaching small children for ten or fifteen years is far more imaginable than the prospect of doing it for fifty. In fact, the schoolmarms of yesterday probably had a similar thought in mind.

At the national level one hears frequent calls for "systemic reform" in education. Usually this means that some reform effort, usually involving curriculum, pedagogy or special opportunities for students and teachers, is supported by various entities within the system and has been made a permanent part of an institution, to be continued indefinitely. Sustainability of an intervention is an important consideration and is laudable. Unfortunately, rarely does the term "systemic" in these contexts refer to an actual change to the way the education system works that would allow the system itself to function more effectively. Yet this kind of change is exactly what is needed to make room for real improvements in quantitative literacy as well as other critical domains. 